\title{
DISCOMFORT DURING LATERAL ACCELERATION: INFLUENCE OF SEAT CUSHION
} AND BACKREST

\author{
George F. Beard ${ }^{a}$ and Michael J. Griffin ${ }^{b}$ \\ Human Factors Research Unit \\ Institute of Sound and Vibration Research \\ University of Southampton \\ Highfield \\ Southampton \\ SO17 1BJ, \\ United Kingdom \\ g.beard@soton.ac.uk \\ m.j.griffin@soton.ac.uk ${ }^{b}$
}

Correspondence concerning this article should be addressed to:

Michael J. Griffin,

Human Factors Research Unit,

University of Southampton,

Highfield,

Southampton, SO17 1BJ,

United Kingdom.

Telephone: +44 (0) 2380592277

Email: m.j.griffin@soton.ac.uk 


\begin{abstract}
Lateral acceleration causes discomfort but how the discomfort depends on the frequency of acceleration or characteristics of seating is poorly understood. Using magnitude estimation, twelve male subjects rated the discomfort caused by lateral oscillation at eight frequencies $(0.2$ to $1.0 \mathrm{~Hz}$ ) across four seating conditions (a rigid seat and a train seat, both with and without backrests). Discomfort increased with increasing frequency of lateral acceleration in a similar manner for all four seating conditions. However, at all frequencies and with both seats there was less discomfort when sitting with backrest support than without. Least discomfort occurred on the train seat with backrest and greatest discomfort on the rigid seat without backrest. Current standards predict an additive effect of backrest on vibration discomfort, but the findings show that low frequency lateral acceleration can cause less discomfort when sitting with a backrest than when sitting on the same seat without a backrest.
\end{abstract}

Keywords: vibration, seating, discomfort 


\section{Introduction}

When a moving vehicle changes the direction of travel, the drivers and passengers must counteract lateral forces if they are to remain upright. While standing or walking, postural stability may be maintained by holding or leaning on a support, or adjusting the location of the feet (e.g., Thuong and Griffin, 2011; Sari and Griffin, 2010). While seated, postural stability is maintained by friction from contact with a backrest (e.g., Corlett and Eklund, 1984; Carcone and Keir, 2007), by differential downward forces at the ischial tuberosities and at the feet (e.g. Helander et al., 1987; Porter et al., 2003), and by muscle activity (e.g., Robertson and Griffin, 1989; Farah et al., 2006; Gallais, 2007). The lateral forces result in discomfort (e.g., Miwa, 1967; Donati, 1983; Corbridge and Griffin, 1986; Wyllie and Griffin, 2007), but there has been little systematic investigation of how the discomfort depends on the characteristics of the lateral motion or the characteristics of the seating.

When sitting on a flat horizontal rigid seat with a flat vertical rigid backrest, the discomfort caused by lateral sinusoidal acceleration has been reported to be greatest at frequencies of oscillation between 1.25 and $2.0 \mathrm{~Hz}$ (Corbridge and Griffin, 1986). When sitting on a similar rigid seat, both with and without a backrest, sensitivity to lateral acceleration caused by either lateral motion or roll through gravity, was found to increase with increasing frequency of oscillation from 0.2 to $1.6 \mathrm{~Hz}$ (Wyllie and Griffin, 2007). At frequencies less than $0.4 \mathrm{~Hz}$, lateral acceleration in the plane of the seat arising from roll through the gravity vector caused similar discomfort to the same acceleration produced by lateral oscillation. However, at frequencies greater than $0.4 \mathrm{~Hz}$, roll oscillation caused greater discomfort than the equivalent lateral oscillation. Compared to sitting with no backrest, wearing a four-point harness with a full height backrest increased discomfort from lateral oscillation at frequencies greater than $0.4 \mathrm{~Hz}$ and increased discomfort from roll oscillation at frequencies greater than $0.63 \mathrm{~Hz}$ (Wyllie and Griffin, 2007). During lateral oscillation at frequencies between 0.5 and $3.15 \mathrm{~Hz}$, the relative displacement between the head and the seat decreases with increasing height of a backrest (Brett and Griffin, 1991), suggesting that taller backrests offer greater lateral support (i.e., forcing the upper-body to move inphase with the motion). Any discomfort from the muscular exertion required to maintain an upright posture may therefore be expected to reduce when there is increased lateral support from a backrest. Conversely, discomfort may be increased due to the increased transmission of vibration to the upperbody when supported by a backrest, consistent with greater discomfort when wearing a four-point harness with a backrest than when not using a backrest (Wyllie and Griffin, 2007) - suggesting the increased transmission of motion to the upper-body when wearing the harness with a backrest was a more dominant cause of discomfort than either relative motion between the head and the seat or the muscular effort required to maintain an upright posture when sitting without the harness or a backrest.

Currently standardised methods of predicting discomfort caused by whole-body vibration suggest greater vibration discomfort with more contact points between the body and the vibrating environment (e.g., BS 6841, 1987; ISO 2631-1, 1997). This implies that contact with the backrest of a seat will always increase vibration discomfort, even if it stabilises the body during low frequency lateral oscillation. The standards imply that vibration discomfort can be predicted from the acceleration at the interfaces between the body and a seat (e.g., at the ischial tuberosities and at the back). Since the transmission 
of very low frequency translational vibration to the body is independent of seat compliance (ignoring any roll on compliant seating), the standardised methods predict similar discomfort with rigid and compliant seats at low frequencies.

Previous research has found that backrests affect the movement of the body and can increase vibration discomfort, broadly consistent with current standards for evaluating vibration with respect to discomfort, yet it is widely assumed that seats with backrests are more comfortable. The experiment described here was designed to quantify the extent to which the discomfort caused by lateral oscillation in the range 0.2 to $1.0 \mathrm{~Hz}$ depends on backrest support and seat cushioning. It was hypothesised that the discomfort caused by lateral acceleration would increase as the frequency of oscillation increased from 0.2 to 1.0 $\mathrm{Hz}$, but that the frequency-dependence of discomfort would depend on the both the presence of a backrest and whether the seat was cushioned.

\section{Method}

\subsection{Apparatus}

Motions were produced by a simulator capable of 1-metre of horizontal oscillation. A train seat and a rigid seat were positioned adjacent to each other on the 1.0 by $1.5 \mathrm{~m}$ motion platform (Figure 1). The seats were orientated so that horizontal displacement of the simulator platform provided lateral oscillation.

\section{FIGURE 1 ABOUT HERE}

The rigid seat consisted of a flat horizontal seat pan (510 by $400 \mathrm{~mm}$ ), located $480 \mathrm{~mm}$ above the motion platform, and a flat vertical backrest ( 645 by $650 \mathrm{~mm}$ ). The surfaces of the seat pan and the backrest were covered in hard rubber less than 2-mm thick to increase surface friction. The train seat consisted of a cushioned seat pan ( 510 by $400 \mathrm{~mm}$ ) located $420 \mathrm{~mm}$ above the motion platform with a cushioned backrest ( 520 by $740 \mathrm{~mm}$ ) inclined by 31 degrees relative to gravity (SAE J826, 2008). The backrest was contoured both vertically and horizontally. Cushioned horizontal armrests, $270 \mathrm{~mm}$ above the seat pan, were not used.

Subjects were asked to maintain comfortable upright postures with their hands on their laps and their feet flat on the floor. When backrest contact was required, subjects were asked to ensure the whole back (but not the head) was in contact with the backrest. During motion exposure, subjects wore headphones producing white noise at $65 \mathrm{~dB}(\mathrm{~A})$ in order to mask any sounds from the simulator. The experimenter communicated with subjects through a microphone connected to headphones which interrupted the white noise. Subjects wore a loose lap belt for safety.

\subsection{Design}

The experiment adopted a repeated measures (within-subjects) design. Subjects were exposed to a series of pairs of motion stimuli whilst seated in one of four seating conditions (the rigid seat with and without backrest contact, and the cushioned train seat with and without backrest contact - see Figure 
2 ) in each of four experimental sessions. The method of magnitude estimation was used to rate the discomfort of test stimuli relative to the discomfort caused by a reference stimulus.

Each session consisted of three parts. In part 1 (equivalent comfort contours) subjects were required to rate the discomfort of test stimuli relative to the discomfort caused by a reference stimulus $(0.5-\mathrm{Hz}$ lateral oscillation at $0.2 \mathrm{~ms}^{-2}$ r.m.s.), where the reference and test stimuli were presented in the same seating condition. In part 2 (cross-over test) subjects rated the discomfort of test stimuli relative to the discomfort caused by a reference stimulus, where the reference and the test stimuli were presented in different seating conditions. In part 3 (body map) subjects indicated the location of the body where they felt most discomfort using a labelled diagram of the body (Figure 3).

The order of presentation of motion stimuli within each session was fully randomised for each subject. The order of the four sessions was varied for each subject using a Latin square.

\section{FIGURES 2 AND 3 ABOUT HERE}

\subsection{Motion stimuli}

Lateral oscillatory motion was presented at each of the eight preferred one-third octave centre frequencies from 0.2 to $1.0 \mathrm{~Hz}$. In part 1 (equivalent comfort contours), each frequency was presented at eight magnitudes (in logarithmic series between 0.08 and $0.40 \mathrm{~ms}^{-2}$ r.m.s.), except for $0.2 \mathrm{~Hz}$ where the two highest magnitudes were not presented due to simulator displacement limitations. The same reference motion was used throughout the experiment: a $0.5-\mathrm{Hz}$ lateral oscillation at $0.2 \mathrm{~ms}^{-2} \mathrm{r}$.m.s. In part 2 (cross-over test), eight magnitudes were presented at $0.5 \mathrm{~Hz}$ only. In part 3 (body map), each frequency was presented at $0.08,0.16$ and $0.40 \mathrm{~ms}^{-2}$ r.m.s. (except for $0.2 \mathrm{~Hz}$, where $0.25 \mathrm{~ms}^{-2}$ r.m.s. was the highest magnitude possible). All motion stimuli were transient waveforms of approximately $11-$ $s$ duration (to the nearest half-cycle) generated from the product of a sine wave of the desired frequency and a half-sine of the same duration (Figure 4). All motions were generated within MATLAB (version R2009 research) using the HVLab toolbox (version 1.0).

\section{FIGURE 4 ABOUT HERE}

\subsection{Subjects}

Twelve healthy male volunteers aged 18 to 30 years participated in the experiment (median age 25.5 years, inter-quartile range, IQR 23.5 - 26.3 years; median weight $70.9 \mathrm{~kg}$, IQR 60.8 - $82.8 \mathrm{~kg}$; median stature $1.745 \mathrm{~m}$, IQR 169.3 - 179.5). Subjects were recruited from the staff and student population of the University of Southampton.

\subsection{Analysis}

The physical magnitudes of the motion stimuli, $\varphi$, were related to the subjective magnitude estimates, $\psi$, using Stevens' power law (Stevens, 1975):

Eq. 1:

$$
\psi=k \varphi^{n}
$$


The exponent, $n$, (i.e., the rate of growth of discomfort) and the constant, $k$, were determined by linear regression on the logarithmic transformation of Equation 1:

Eq. 2:

$$
\log _{10} \psi=\log 10 k+n \log _{10} \varphi
$$

Values for $n$ and $k$ were determined for each subject at each frequency within each seating condition. Equivalent comfort contours for a subjective magnitude, $\psi$, of 100 were calculated for each subject and each seating condition using Equation 1.

The data from part 2 (cross-over test) were used to calculate correction factors to adjust the equivalent comfort contours obtained in part 1 so that the relative discomfort across different seating conditions could be examined. Correction factors were calculated using Equation 3:

Eq. 3: $\quad$ Correction factor $=\left(\varphi_{\text {cross-over }}\right) /\left(\varphi_{\text {Part 1 }}\right)$

where $\varphi_{\text {Part } 1}$ is the acceleration magnitude of a $0.5-\mathrm{Hz}$ test motion in part 1 that caused discomfort equivalent to that caused by the reference motion (i.e., $0.5 \mathrm{~Hz}$ at $0.20 \mathrm{~ms}^{-2}$ r.m.s.) in the same seating condition as the test stimulus, and $\varphi$ cross-over is the acceleration magnitude of a $0.5-\mathrm{Hz}$ test motion in part 2 (the cross-over test) that caused discomfort equivalent to that caused by the same reference motion (i.e., $0.5 \mathrm{~Hz}$ at $0.20 \mathrm{~ms}^{-2}$ r.m.s.) in a different seating condition from the test stimulus. The rigid seat with backrest contact was used as a common reference so that the relative discomfort experienced in all four seating conditions could be compared. The acceleration magnitudes used to define $\varphi_{\text {Part } 1}$ and $\varphi$ cross-over were median values calculated from the 12 subjects. Relative equivalent comfort contours for the four seating conditions were generated by applying the correction factors to the median equivalent comfort contours calculated from part 1. Individual equivalent comfort contours from part 1 were also adjusted using the same correction factors in order to allow statistical comparisons across seating conditions.

The data from part 3 (body map) were used to assess the effect of the frequency and magnitude of lateral oscillation on the location of most discomfort.

The Friedman test was used to investigate the overall effect of frequency and seating on the rates of growth of discomfort and the equivalent comfort contours. The Wilcoxon matched-pairs signed ranks test was used to examine differences in rates of growth of discomfort and equivalent comfort contours between specific frequencies and specific seating conditions. The McNemar dichotomous variables test was used to examine differences in the location of discomfort across specific seating conditions. Median rates of growth of discomfort and median equivalent comfort contours were calculated to identify overall trends in the data.

\section{Results}

\subsection{Rate of growth of vibration discomfort}

The rate of growth of discomfort varied with the frequency of vibration for the rigid seat with backrest ( $p$ $=0.003$; Friedman), but not for the rigid seat without backrest, or for the train seat, either with or without 
backrest ( $p=0.047,0.948$ and 0.110 , respectively; Figure 5$)$. The seating condition had no significant effect on the rate of growth of discomfort at any frequency ( $p>0.05$; Friedman).

\section{FIGURE 5 ABOUT HERE}

\subsection{Effect of frequency of oscillation on vibration discomfort}

Equivalent comfort contours obtained from each subject in each seating condition were adjusted (as described above) to determine the vibration magnitude required at each frequency to produce vibration discomfort equivalent to that caused by the common reference motion: $0.5 \mathrm{~Hz} 0.20 \mathrm{~ms}^{-2}$ r.m.s. lateral oscillation on the rigid seat with backrest (Figure 6). The frequency-dependence of equivalent comfort contours will change with the magnitude of the vibration (e.g., Morioka and Griffin, 2006). However, because there was no difference in the rate of growth of discomfort between seating conditions, the relative discomfort between seats will be independent of vibration magnitude. The equivalent comfort contours shown here are therefore constructed for only one magnitude of vibration. The acceleration associated with equivalent comfort decreased with increasing frequency of vibration for the train seat with backrest $(p=0.009$; Friedman) and the rigid seat without backrest $(p=0.022)$, but not for the train seat without backrest $(p=0.054)$ or the rigid seat with backrest $(p=0.125$; Friedman).

\section{FIGURE 6 ABOUT HERE}

\subsection{Effect of seating on vibration discomfort}

At every frequency, the adjusted equivalent contours were highly dependent on seating condition $(p<$ 0.01; Friedman). Greater magnitudes of lateral oscillation were required to cause equivalent discomfort when seated on the train seat with backrest than when seated on: (i) the train seat without backrest, at all frequencies except 0.2 and $1.0 \mathrm{~Hz}(p<0.01$; Wilcoxon), (ii) the rigid seat with backrest, at all frequencies except 0.315 and $1.0 \mathrm{~Hz}(p<0.01)$, and (iii) the rigid seat without backrest, at all frequencies except 0.25 and $0.315 \mathrm{~Hz}(p<0.01)$. Lower magnitudes of lateral oscillation were required to cause discomfort on the rigid seat without backrest than on both the train seat without backrest at $0.63 \mathrm{~Hz}$ ( $p$ $<0.01$; Wilcoxon) and on the rigid seat with backrest at 0.4 and $0.63 \mathrm{~Hz}(p<0.01$; Wilcoxon).

\subsection{The location of discomfort}

There were no clear effects of the magnitude of oscillation on the locations in the body where subjects felt most discomfort, so the data were pooled across the three magnitudes at each frequency. Greatest discomfort occurred more frequently at the head, neck, or shoulders during $0.5-\mathrm{Hz}$ oscillation on the train seat with backrest than on the rigid seat without backrest ( $p=0.006$; McNemar). Greatest discomfort occurred more frequently at the ischial tuberosities on the rigid seat (with and without backrest) than on the train seat without backrest during $0.5-\mathrm{Hz}$ oscillation $(p=0.008$ and 0.006 , respectively; McNemar), and more frequently on the rigid seat without backrest than the train seat with backrest during $1-\mathrm{Hz}$ oscillation ( $p=0.006$; McNemar). These patterns are illustrated in Figure 7. No other statistically significant differences in the location of greatest discomfort were found. 


\section{Discussion}

\subsection{Rate of growth of discomfort}

A greater rate of growth of discomfort implies a greater increase in the magnitude of discomfort associated with a unit increase in the magnitude of acceleration. Rates of growth of discomfort did not vary between conditions with and without backrest on either the rigid seat or the train seat, although there were statistically significant changes with the frequency of lateral oscillation on the rigid seat with backrest but not on the train seat. Previous research with lateral oscillation on a rigid seat reported no effects on the rate of growth of discomfort of using a rigid backrest and four-point harness, consistent with the present study (Wyllie and Griffin, 2007). During lateral oscillation of a rigid seat without backrest, the previous study found decreasing rates of growth of discomfort with increasing frequency of oscillation from 0.2 to $1.6 \mathrm{~Hz}$, with a more consistent effect of frequency than found here. The present study investigated acceleration magnitudes between 0.08 and $0.40 \mathrm{~ms}^{-2}$ r.m.s. with a $0.5-\mathrm{Hz}$ reference at $0.20 \mathrm{~ms}^{-2}$ r.m.s., somewhat less uncomfortable than the 0.2 to $0.63 \mathrm{~ms}^{-2}$ r.m.s. range with a $0.5-\mathrm{Hz}$ reference at $0.315 \mathrm{~ms}^{-2}$ r.m.s. used by Wyllie and Griffin (2007). Stevens (1975) assumed the exponent in the power law was independent of the magnitude of physical stimuli, but this may not apply with all physical stimuli - a dependence of the rate of growth of discomfort on vibration magnitude might explain the discrepancy between the current findings and those reported by Wyllie and Griffin (2007).

\subsection{Equivalent comfort contours}

In all four seating conditions, the lateral acceleration required to produce equivalent discomfort decreased by approximately $3 \mathrm{~dB}$ per octave as the frequency increased from 0.2 to $1.0 \mathrm{~Hz}$ (i.e., sensitivity increased with increasing frequency). A similar effect of frequency has been reported for lateral vibration of a rigid seat without backrest over the frequency range 0.2 to $1.6 \mathrm{~Hz}$, but a greater rate of decrease (approximately $6 \mathrm{~dB} /$ octave) was found for a rigid seat with four-point harness and backrest (Wyllie and Griffin, 2007; Figure 8). This is consistent with the harness reducing discomfort at lower frequencies but increasing discomfort at higher frequencies.

At all frequencies, lateral oscillation caused least discomfort when sitting on the train seat with backrest. Compared to the rigid seat without backrest (i.e., the seat associated with greatest discomfort), the train seat with backrest allowed approximately a two-fold increase in vibration magnitude for the same level of vibration discomfort (Figure 6). The rigid seat without backrest and the cushioned train seat without backrest produced similar discomfort at all frequencies (Figure 6), consistent with no large differences in discomfort during lateral oscillation at $1 \mathrm{~Hz}$ when seated on a flat rigid seat without backrest or a foam cushion without backrest as reported by Moxley et al. (2011).

It has been suggested that the overall discomfort, $\psi$, of a seat can be predicted by summing the static discomfort, $\psi_{\mathrm{s}}$, and the dynamic discomfort, $\psi_{\mathrm{v}}$ (Ebe and Griffin, 2000):

Eq. 4:

$$
\psi=a+b \phi_{s}^{n_{s}}+c \varphi_{v}^{n_{v}}
$$


where $\varphi_{\mathrm{s}}$ is a measure of the seat pan stiffness (causing static discomfort), $n_{\mathrm{s}}$ is the rate of growth of static discomfort, $\varphi_{v}$ is the vibration acceleration magnitude (causing dynamic discomfort), $n_{v}$ is the rate of growth of dynamic discomfort, and $a, b$, and $c$ are constants. Without asking subjects to distinguish between static and dynamic discomfort, the present study found that greater vibration magnitudes were required to cause a given level of discomfort on the train seat with backrest than on the other three seats. The above model (Equation 4) allows the possibility that the greater comfort on the train seat with backrest was partially due to greater static comfort with this seat.

A lower magnitude of lateral acceleration was required to produce equivalent discomfort on the rigid seat without backrest than on the rigid seat with backrest, indicating that the backrest reduced discomfort (with a statistically significant benefit at 0.4 and $0.63 \mathrm{~Hz}$ ). This differs from the increasingly detrimental effect of a backrest with harness as the frequency increases from 0.2 to $1.0 \mathrm{~Hz}$ (Wyllie and Griffin, 2007; Figure 8). This detriment is also apparent at 1.6 and $2 \mathrm{~Hz}$ when comparing contours obtained with a backrest without harness by Corbridge and Griffin (1986) with those obtained with backrest and harness by Wyllie and Griffin (2007), as shown in Figure 8. The increased discomfort with a four-point harness may be due to increased transmission of motion to the upper-body resulting in increased forces at the neck.

\section{FIGURE 8 ABOUT HERE}

In current standards, the discomfort caused by lateral acceleration at frequencies greater than $0.5 \mathrm{~Hz}$ is predicted using frequency weighting $W_{d}$ (BS 6841, 1987; ISO 2631-1, 1997). The asymptotic version of this weighting has sensitivity to acceleration which is independent of frequency from 0.5 to $2 \mathrm{~Hz}$ and then falls in inverse proportion to frequency from 2 to $80 \mathrm{~Hz}$. The realisable version of the frequency weighting has a gradual transition around $2 \mathrm{~Hz}$ and a high pass filter at $0.4 \mathrm{~Hz}$. The reciprocal of the realisable frequency weighting $W_{\mathrm{d}}$ shows some similarity to the current and previous equivalent comfort contours for low frequency lateral oscillation, even though the weighting is not intended for application to frequencies less than $0.5 \mathrm{~Hz}$ (Figure 7). However, relative to other frequencies, it seems that the realisable $W_{\mathrm{d}}$ weighting tends to underestimate the discomfort caused by frequencies less than about $0.3 \mathrm{~Hz}$, except when restrained against a backrest by a harness.

Irrespective of the frequency-dependence, the level of the equivalent comfort contours depends on the seating conditions. British standard 6841 (1987) and International standard 2631-1 (1997) advocate the use of frequency weighting $W_{\mathrm{d}}$ to predict discomfort caused by both lateral oscillation at the seat and lateral acceleration at the backrest, but with sensitivity at the backrest half that at the seat (i.e., a 0.5 multiplying factor is used for lateral acceleration at the backrest). An 'overall ride value' can be predicted from the root-sums-of-squares (r.s.s.) of all weighted inputs, so contact with vibration at a backrest will increase the overall ride value and imply increased discomfort (Griffin, 2007). If the vibration at the seat and the backrest is the same, the r.s.s. of the weighted vibration at the seat and the back will be about $12 \%$ greater when vibration at the backrest is included. Wyllie and Griffin (2007) found that wearing a full harness that forced contact with a backrest increased discomfort, although the increase varied with frequency and was greater than implied by the standards over the range 0.8 to $1.6 \mathrm{~Hz}$. The present study with both a rigid seat and a train seat found that leaning against a backrest without a harness 
tended to reduce discomfort at all frequencies between 0.2 and $1.0 \mathrm{~Hz}$. It seems that an intermediate situation is optimum: contact with a backrest can help to reduce movements responsible for discomfort but forcing the back to move with a backrest can increase strain in the body. Without a harness, people may be able, to some extent, to control their contact with a backrest so that it is beneficial and not detrimental.

\subsection{The location of discomfort}

During $0.5-\mathrm{Hz}$ lateral oscillation, the location of greatest discomfort occurred more frequently at the head, neck, and shoulders on the train seat with backrest than in any of the other three seating conditions (Figure 7). Either the train seat with backrest increased discomfort at the head, neck, and shoulders or it decreased discomfort at other locations of the body. The $740 \mathrm{~mm}$ high backrest resulted in most subjects having the tops of their shoulders in contact with the seat, which is likely to have increased the transmission of vibration to the shoulders, neck, and head (Paddan and Griffin, 1988). The contouring of the train seat backrest also provided lateral support so the upper-body was less free to make compensatory adjustments during oscillation. The contact with the backrest may have increased lateral acceleration of the upper-body, and without support for the head this may have resulted in greater strain around the neck. When sitting with the backrest there may also have been reduced discomfort at other locations, leaving the head, neck, and shoulders as the dominant locations for discomfort. For example, the backrest may have reduced back muscle activity associated with maintaining an upright posture during lateral oscillation.

During lateral oscillation between 2 and $64 \mathrm{~Hz}$ on a rigid seat without backrest, discomfort was localised mainly at the ischial tuberosities (Whitham and Griffin, 1978). In this study, greatest discomfort also occurred most frequently at the ischial tuberosities when sitting on the rigid seat without backrest during $0.5-\mathrm{Hz}$ and $1-\mathrm{Hz}$ oscillation (Figure 7). When stationary and sitting upright, the weight of the body is supported with similar pressure at both ischial tuberosities, but during lateral oscillation with no backrest the sway of the body is partially restrained by alternating increases in pressure at the two ischial tuberosities. Backrests help to reduce pressure on the ischial tuberosities when static (e.g., Vos et al, 2006; Kyung and Nussbaum, 2008) and also help to constrain the swaying of the body during oscillation. The reduction in the weight supported at the ischial tuberosities and the decreased need to control sway by increasing pressure, is consistent with reduced discomfort at the ischial tuberosities when sitting with a backrest during low frequency lateral oscillation.

\subsection{Practical implications}

The characteristics of a seat and the sitting posture have been shown to influence the severity of vibration discomfort, and the location of discomfort, caused by low frequency lateral vibration. With a rigid seat and a compliant train seat, contact with the backrest reduced the discomfort caused by all frequencies of lateral acceleration between 0.2 and $1.0 \mathrm{~Hz}$. It seems reasonable to assume that the backrests reduced the muscular exertion that is otherwise required to maintain an upright posture during low frequency lateral oscillation (Robertson and Griffin, 1989). Reduced pressure at the ischial tuberosities on the train seat may explain why lateral acceleration caused less discomfort on the train 
seat than the rigid seat. Other factors associated with the configuration of a backrest (e.g., backrest height, inclination, and curvature) may also affect motion discomfort, with effects that may be expected to depend on the type of motion (e.g., lateral oscillation or roll oscillation; Beard and Griffin, 2012). The prediction of seating comfort in an environment with low frequency acceleration should therefore consider how the seat characteristics control the motions of the seat occupant as well as how the motion is transmitted through the seat to the surface of the human body.

\section{Conclusions}

The discomfort caused by lateral acceleration increases with increasing frequency of oscillation from 0.2 to $1.0 \mathrm{~Hz}$. When applied with a band-limiting filter, the frequency weighting $W_{\mathrm{d}}$ in current standards gives a useful indication of how discomfort depends on the frequency of lateral oscillation in the range 0.3 to $1.0 \mathrm{~Hz}$, but it underestimates the discomfort caused by lower frequencies. Current standards predict that contact with a backrest will increase vibration discomfort, but low frequency lateral acceleration causes less discomfort when sitting supported by a backrest than when sitting on the same seat without backrest support. Sitting on a rigid seat, either with or without a backrest, resulted in greater motion discomfort than sitting on a compliant seat, with greater incidence of discomfort at the ischial tuberosities. The combination of a compliant seat cushion with a high, contoured, slightly reclined backrest was associated with least discomfort from lateral motions in the frequency range 0.2 to $1.0 \mathrm{~Hz}$. 


\section{References}

Beard, G.F., Griffin, M.J., 2012. Discomfort caused by lateral, roll and fully roll-compensated lateral oscillation. Ergonomics, DOI:10.1080/00140139.2012.729613.

Brett, M.W., Griffin, M.J., 1991. Effect of height of backrest support on head motion during exposure to low frequency lateral vibration. In, Proceedings of the Ergonomics Society's 1991 Annual Conference, Southampton, England, 16-19 April 1991.

British Standards Institution, 1987. Measurement and evaluation of human exposure to whole-body mechanical vibration and repeated shock. BS 6841. British Standards Institution, London.

Carcone, S.M., Keir, P.J., 2007. Effects of backrest design on biomechanics and comfort during seated work. Applied Ergonomics. 38, 755-764.

Corbridge, C., Griffin, M.J., 1986. Vibration and comfort: vertical and lateral motion in the range 0.5 to 5.0 Hz. Ergonomics. 29 (2), 249-272.

Corlett, E.N., Eklund, J.A.E., 1984. How does a backrest work? Applied Ergonomics. 15 (2), 11-114.

Donati, P., Grosjean, A., Mistrot, P., Roure, L., 1983. The subjective equivalence of sinusoidal and random whole-body vibration in the sitting position (an experimental study using the 'floating reference vibration' method). Ergonomics. 26, 251-273.

Ebe, K., Griffin, M.J., 2000. Quantitative prediction of overall seat discomfort. Ergonomics. 43 (6), 791-806.

Farah, G., Petit-Boulanger, C., Hewson, D.J., Duchêne, J., 2006. Surface electromyography as a tool to assess the responses of car passengers to lateral accelerations. Part II: Objective comparison of vehicles. Journal of Electromyography and Kinesiology. 16 (6), 677-684.

Gallais, C.H.R. 2007., Effect of the frequency of fore-and-aft sinusoidal whole-body vibration on neck muscle activity. Presented at the $42^{\text {nd }}$ United Kingdom Conference on Human Responses to Vibration, held at ISVR, Southampton, Hampshire, England, 10-12 September 2007.

Griffin, M.J., 2007. Discomfort from feeling vehicle vibration. Vehicle System Dynamics. 45 (7), 679698.

Helander, M., Czaja, S., Drury, C., Cara, J., Burri, G., 1987. An ergonomic evaluation of office chairs. Office: Technology and People. 3, 247-262.

International Organization for Standardization, 1997. Mechanical vibration and shock - evaluation of human exposure to whole-body vibration - Part 1: General requirements. ISO 2631-1. Geneva, Switzerland: International Organization for Standardization.

Kyung, G., Nussbaum, M.A., 2008. Driver sitting comfort and discomfort (part II): Relationships with and prediction from interface pressure. International Journal of Industrial Ergonomics. 38, 526-538.

Miwa, T., 1967. Evaluation methods for vibration effect. I. Measurements of threshold and equal sensation contours of whole-body for vertical and horizontal vibrations. Industrial Health. 5, 183-205. 
Morioka, M., Griffin, M.J., 2006. Magnitude-dependence of equivalent comfort contours for fore-and-aft, lateral and vertical whole-body vibration. Journal of Sound and Vibration, 298, 755-772.

Moxley, P.R., Morioka, M., Griffin, M.J., 2011. Discomfort during lateral whole-body vibration: influence of seat pan form. Presented at the 46th United Kingdom Conference on Human Response to Vibration, held at the Health and Safety Laboratory and the Health and Safety Executive, Buxton. 20 - 22 September 2011.

Paddan, G.S., Griffin, M.J., 1988. The transmission of translational seat vibration to the head - II. Horizontal seat vibration. Journal of Biomechanics. 21 (3), 199-206.

Porter, J.M., Gyi, D.E., Tait, H.A., 2003. Interface pressure data and the prediction of driver discomfort in road trials. Applied Ergonomics. 34, 207-214.

Robertson, C.D., Griffin, M.J., 1989. Laboratory studies of the electromyographic response to wholebody vibration. ISVR Technical Report 184. University of Southampton, Southampton UK.

Society of Automotive Engineers (SAE) Standard, 2008. Devices for use in defining and measuring vehicle seating accommodation. SAE J826. Society of Automotive Engineers, Warrendale, Pennsylvania, United States of America.

Sari, M., Griffin, M.J., 2010. Effect of hand support on discomfort or difficulty when walking and perturbed by lateral oscillation. 45th United Kingdom Conference on Human Responses to Vibration, held at Institute of Naval Medicine, Alverstoke, Gosport, PO12 2DL, England, 6 - 8 September 2010. Stevens, S.S., 1975. Psychophysics: introduction to its perceptual, neural, and social prospects. Transaction Publishers, Oxford.

Thuong, O., Griffin, M.J., 2011. The vibration discomfort of standing persons: the effect of body supports. Proceedings of the Institution of Mechanical Engineers, Part F: Journal of Rail and Rapid Transit. 225 (2), 228-235.

Vos, G.A., Congleton, J.J., Moore, J.S., Amendola, A.A., Ringer, L., 2006. Postural versus chair design impacts upon interface pressure. Applied Ergonomics. 37 (6). 619-628.

Whitham, E.M., Griffin, M.J., 1978. The effects of vibration frequency and direction on the location of areas of discomfort caused by whole-body vibration. Applied Ergonomics. 9 (4), 231-239.

Wyllie, I.H., Griffin, M.J., 2007. Discomfort from sinusoidal oscillation in the roll and lateral axes at frequencies between 0.2 and $1.6 \mathrm{~Hz}$. Journal of the Acoustical Society of America. 121 (5), 26442654. 


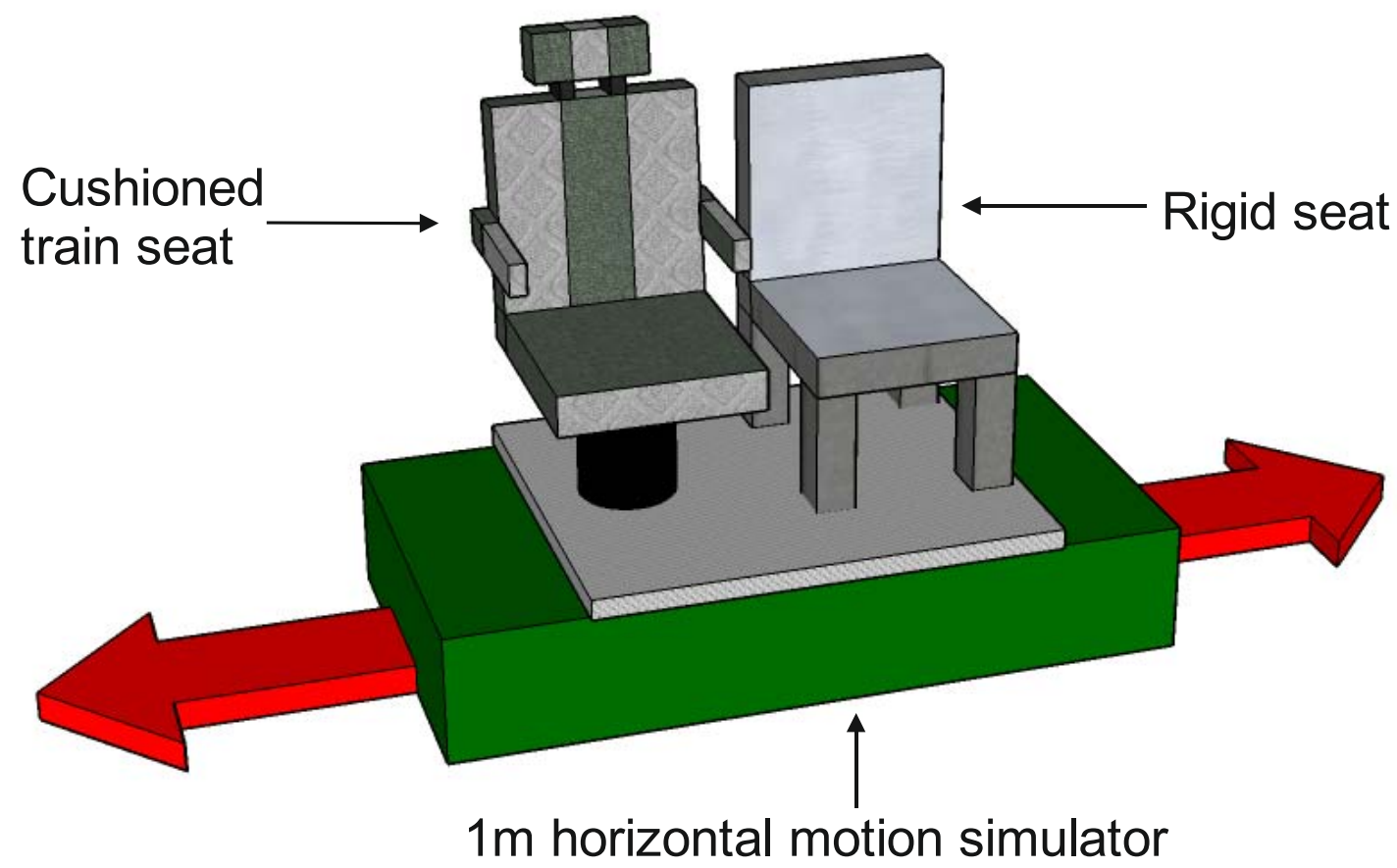

Figure 1 Diagrammatic representation of experimental apparatus (train seat and rigid seat positioned adjacent on 1-metre horizontal simulator). 

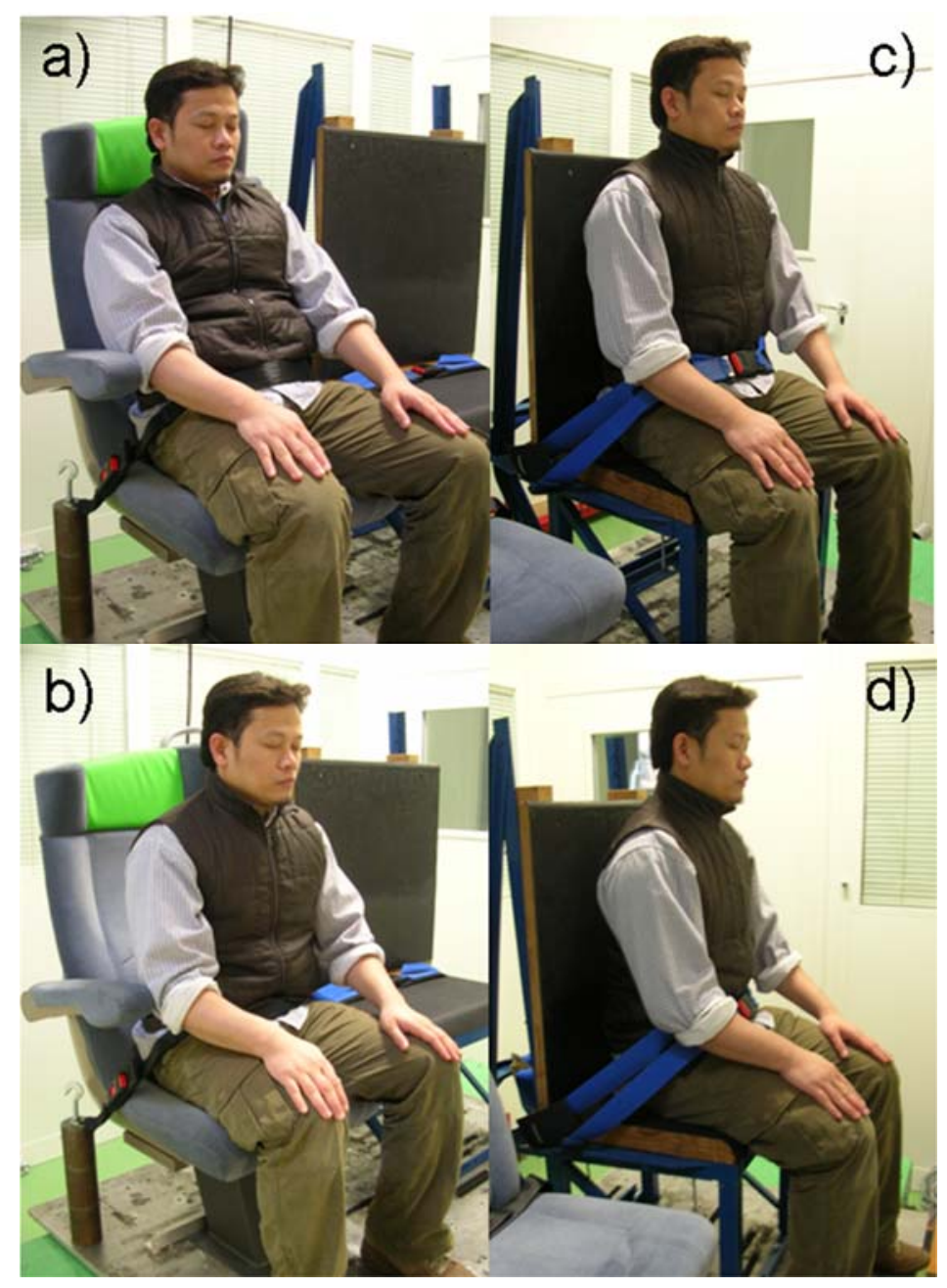

Figure 2 The four seating conditions: (a) train seat with backrest, (b) train seat without backrest, (c) rigid seat with backrest, and (d) rigid seat without backrest. 


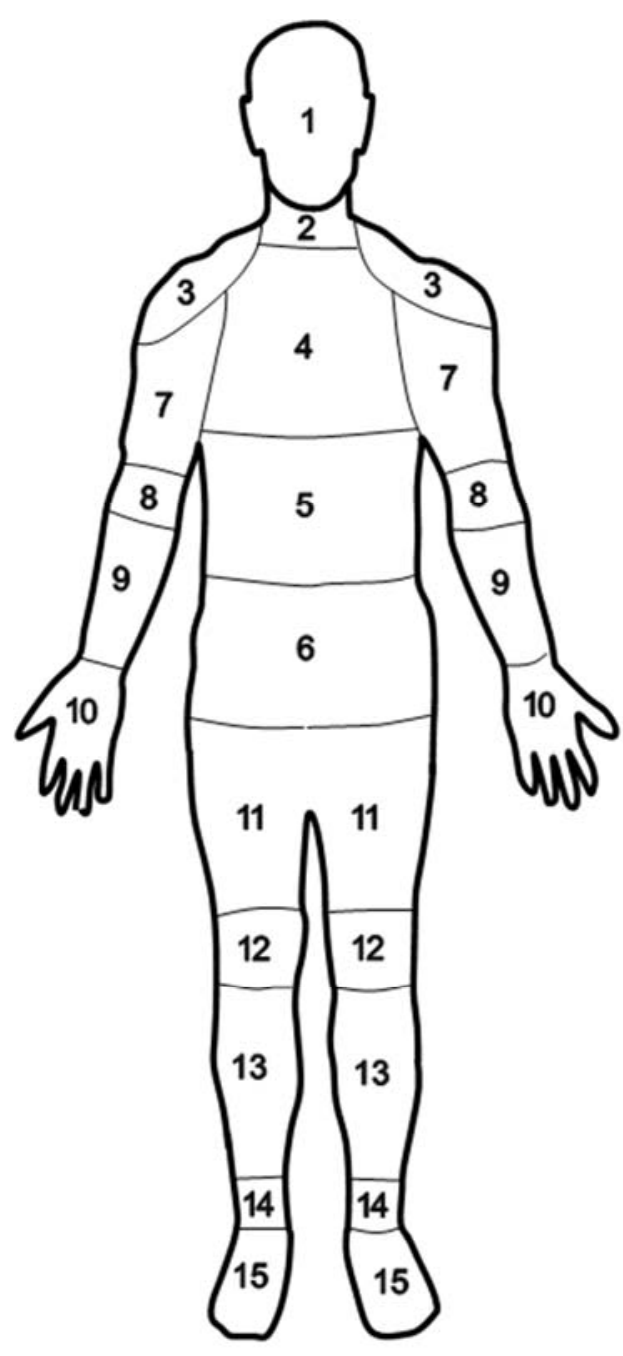

FRONT

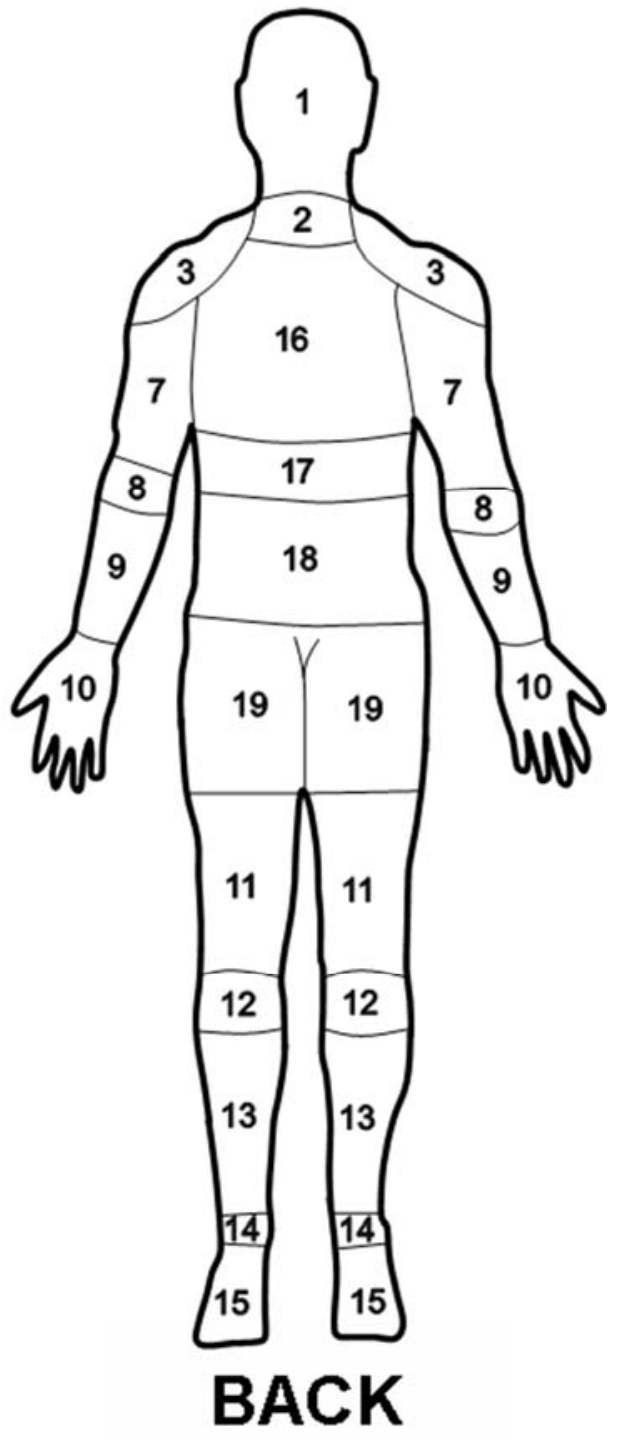

Figure 3 Labelled diagram of the human body (body map) used by subjects to indicate the location of most discomfort in Part 3. 
Beard, G. F. \& Griffin, M. J. Jul 2013 In : Applied Ergonomics. 44, 4, p. 588-594

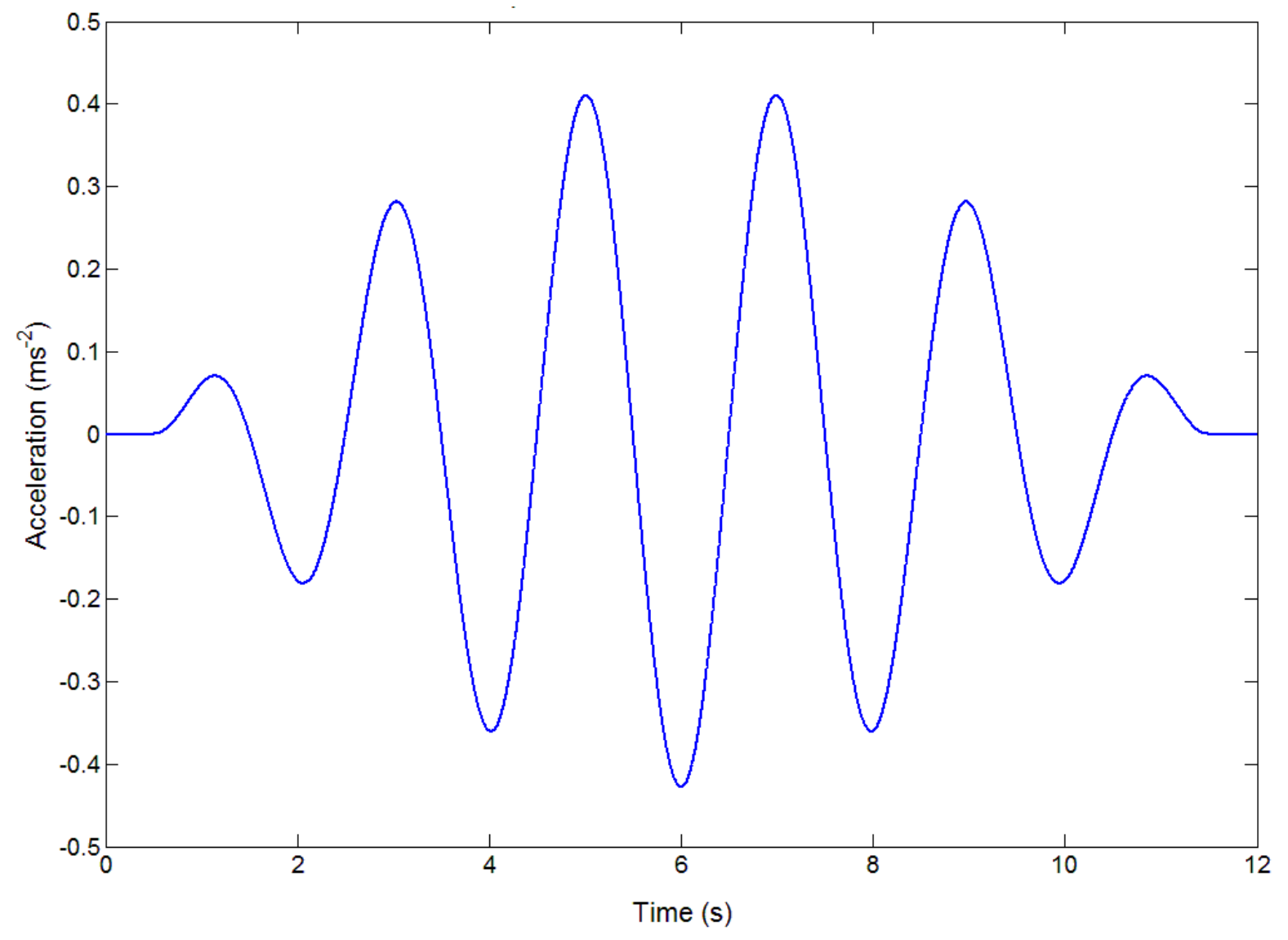

Figure 4 Example waveform of transient lateral motion stimuli $\left(0.5 \mathrm{~Hz}\right.$ oscillation at $0.2 \mathrm{~ms}^{-2}$ r.m.s.). 


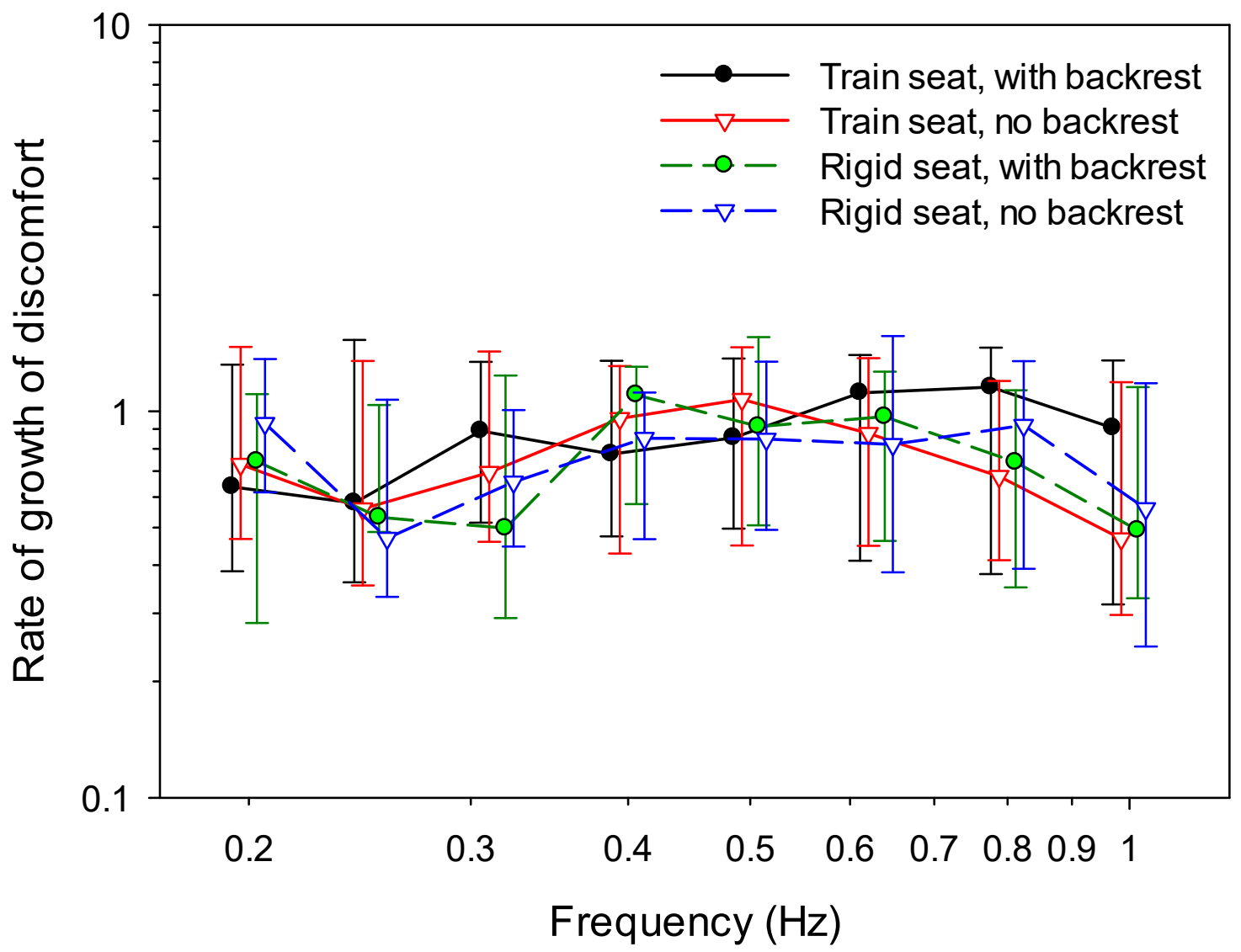

Figure 5 Rates of growth of discomfort for lateral oscillation on a rigid seat and a cushioned train seat with and without backrests. Medians and inter-quartile ranges for 12 subjects. 


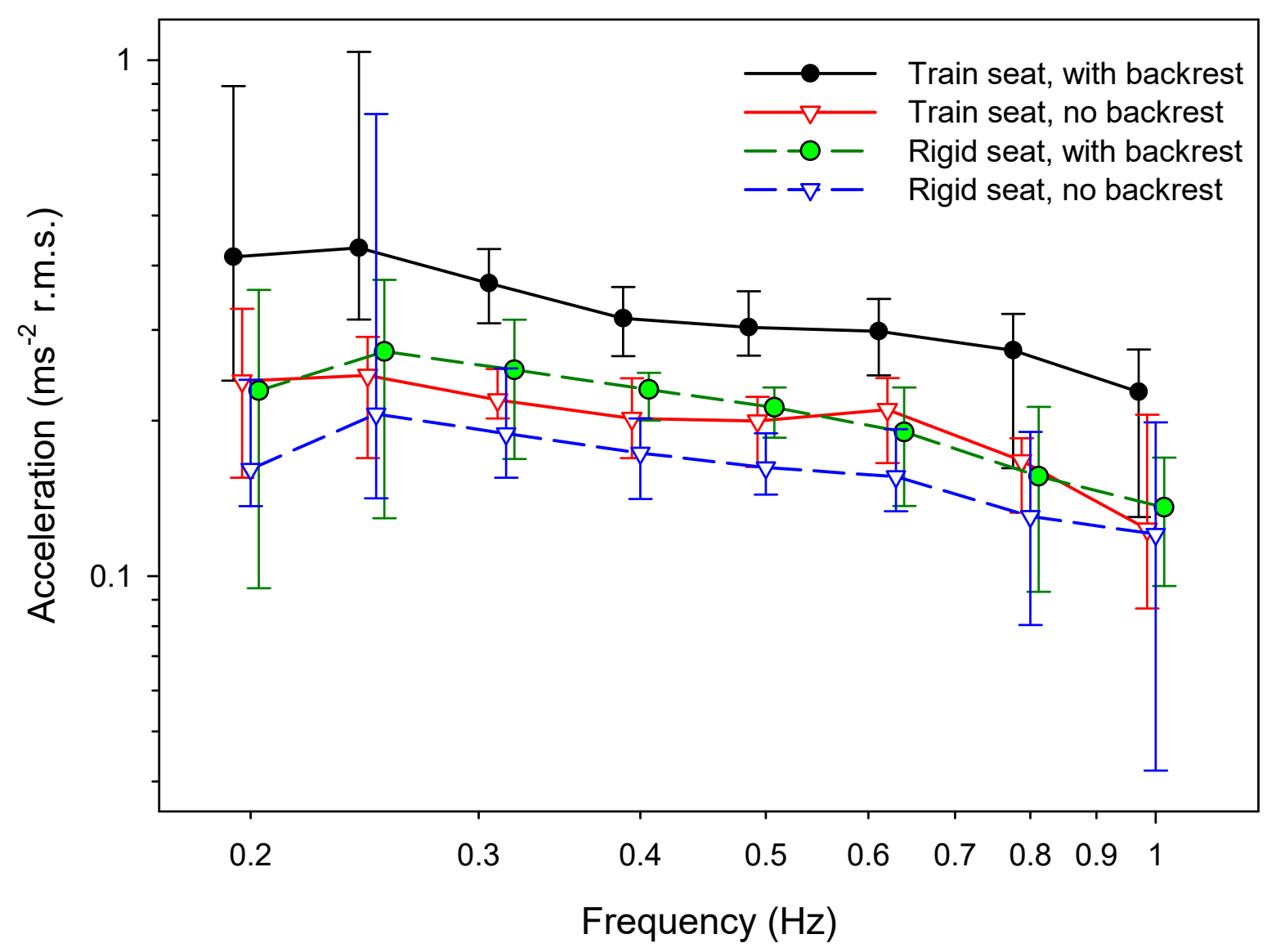

Figure 6 Equivalent comfort contours adjusted to represent discomfort equivalent to $0.5 \mathrm{~Hz}$ at 0.2 $\mathrm{ms}^{-2} \mathrm{rms}$. on a rigid seat with backrest. Medians and inter-quartile ranges for 12 subjects. 


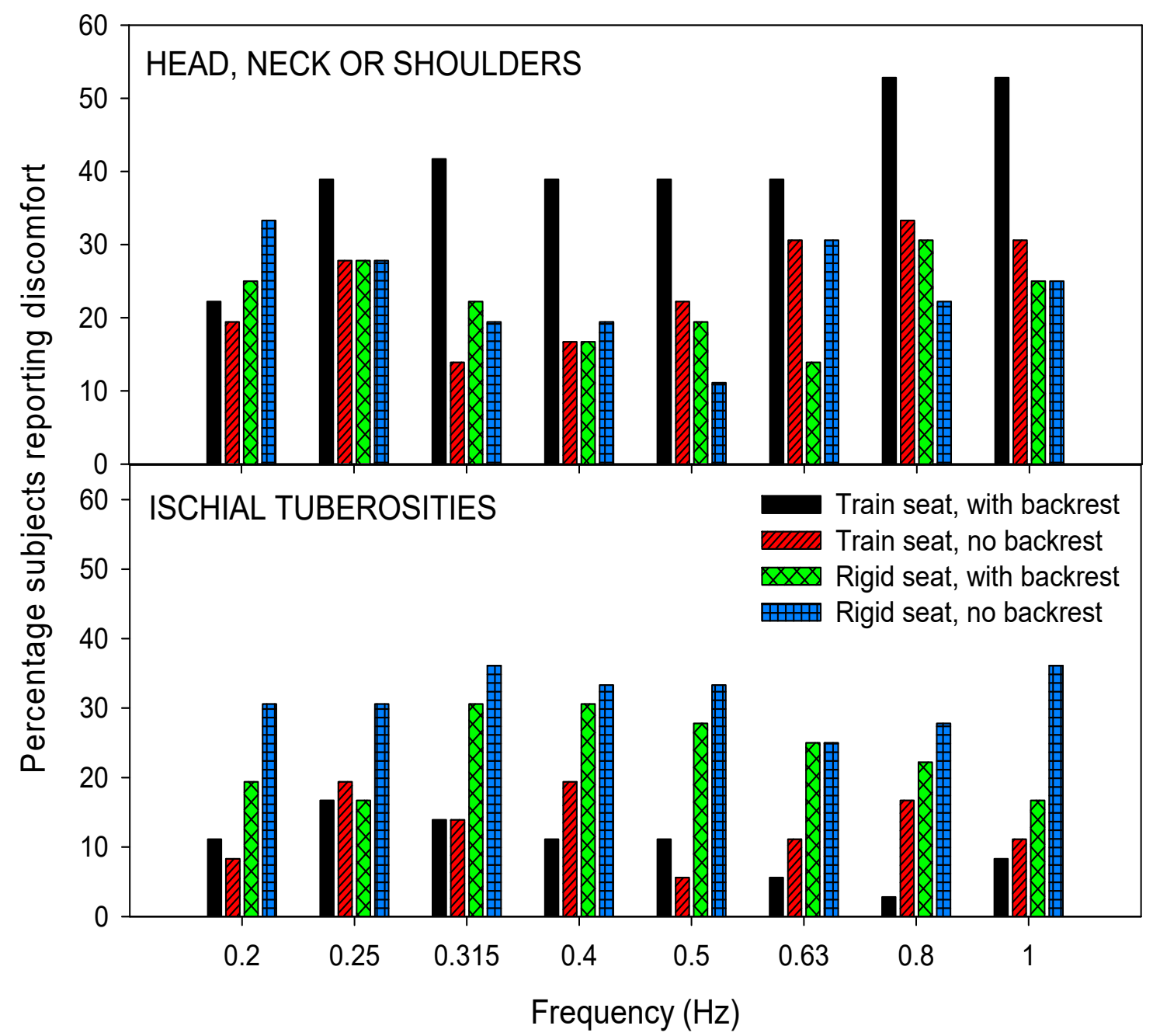

Figure 7 Percentage of subjects reporting most discomfort at the head, neck, or shoulders (top), or at the buttocks (ischial tuberosities) (bottom) during exposure to lateral oscillation across all frequencies with each seating condition. Data from 12 subjects pooled across all three magnitudes of oscillation. 


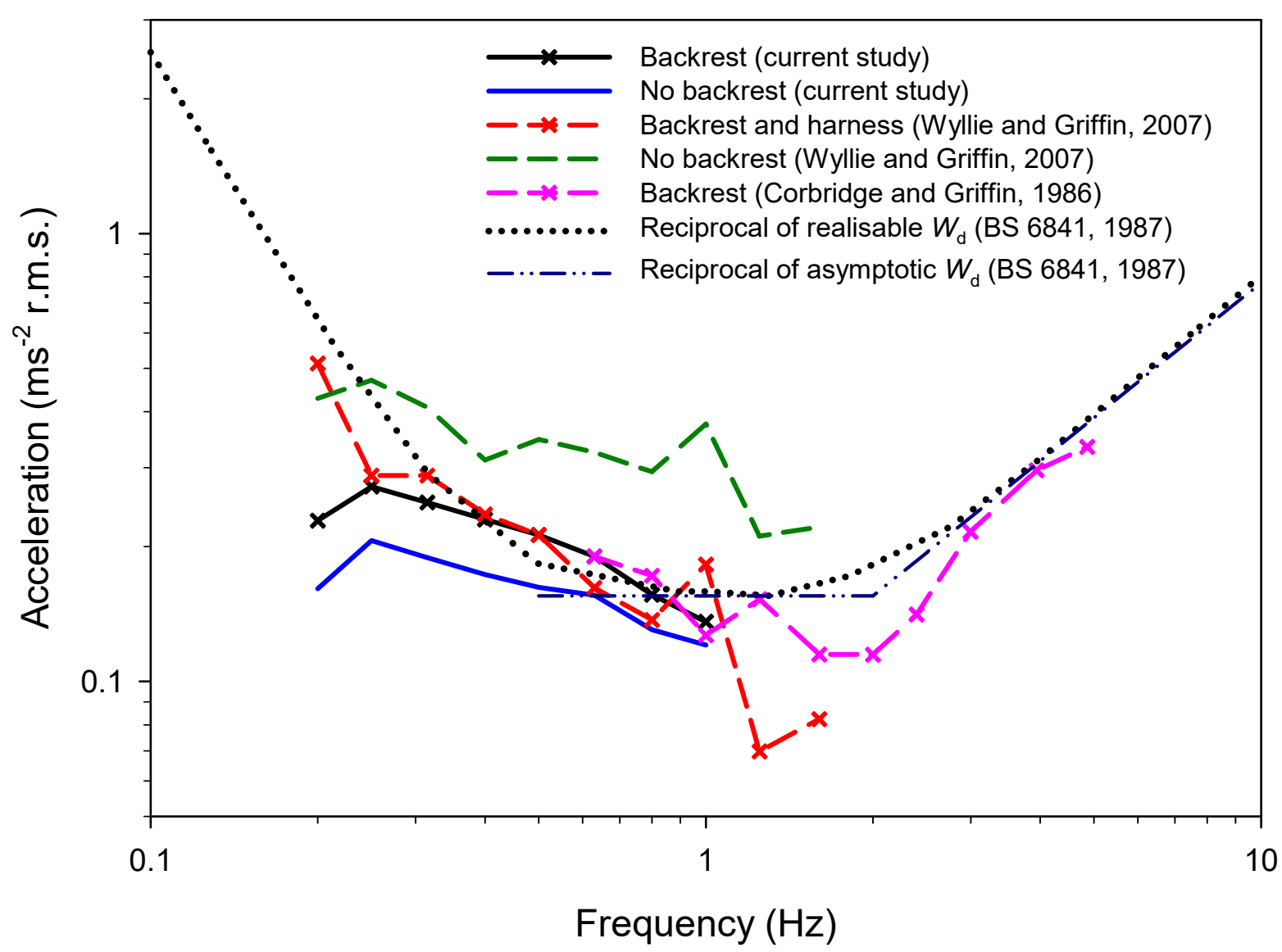

Figure 8 Comparison of median equivalent comfort contours from current study with previous data for lateral oscillation on a rigid seat with and without backrest and frequency weighting $W_{\mathrm{d}}$. The levels of the contours have been adjusted to represent discomfort equivalent to $0.5 \mathrm{~Hz}$ lateral oscillation at 0.2 $\mathrm{ms}^{-2}$ r.m.s. on a rigid seat with backrest. 